\title{
$\mathrm{VII} \mathrm{CINCCI}$
}

VII Colóquio internacional sobre Comércio e Cidade

Fortaleza, 03 a 07 de Novembro de 2020

\section{A importância dos parâmetros urbanísticos para a geração de cidades hospitaleiras}

The importance of urbanistic parameters for the generation of hospitable cities

La importancia de los parámetros de planificación urbana para la generación de ciudades hospitalarias

SEVERINI, Valéria Ferraz; Pós-doutoranda do Programa de Pós-Graduação em Turismo pela Escola de Artes, Ciências e Humanidades da Universidade de São Paulo (EACH-USP)

valferraz@yahoo.com

PANOSSO NETTO, Alexandre; Livre-docente pela Escola de Artes, Ciências e Humanidades da Universidade de São Paulo (EACH-USP)

panosso@usp.br

OLIVEIRA, J. Laize Soares; Mestranda em Turismo pela Escola de Artes, Ciências e Humanidades da Universidade de São Paulo (EACH-USP)

laizeoliveira@usp.br

\section{Resumo}

Os benefícios advindos do turismo nem sempre são percebidos igualmente pelos sujeitos envolvidos na atividade. Hóspedes e anfitriões ocupam e disputam o mesmo território, mas não necessariamente de forma equilibrada. O Estado pode ter o papel de conciliar esses interesses ordenando o espaço urbano para que todos se beneficiem. Políticas públicas que extrapolem as questões econômicas e incorporem aspectos urbanísticos são fundamentais nesse processo, caso contrário a cidade passar a ter territórios "consumidos" pela prática do turismo. É nesta direção que a hospitalidade urbana e a legislação urbanística se aproximam. Este trabalho tem como objetivo principal explorar como certos parâmetros urbanísticos, inseridos nos Planos Diretores, são capazes de garantir a condição de cidade hospitaleira. Utiliza-se como base os resultados parciais da pesquisa de pósdoutorado em andamento que analisa os Planos Diretores das Estâncias Balneárias do Estado de São Paulo. Como método utiliza-se a pesquisa documental e bibliográfica tomando como base os textos, mapas e quadros das referidas leis.

Palavras-chave: Políticas públicas. Hospitalidade Urbana. Espaço Público.

The importance of urbanistic parameters for the generation of hospitable cities 


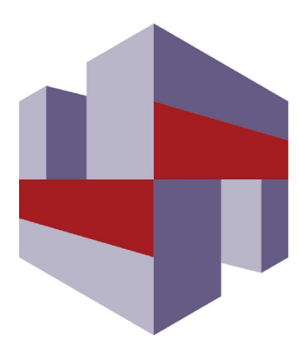

\title{
VII CINCCI
}

VII Colóquio internacional sobre Comércio e Cidade

Fortaleza, 03 a 07 de Novembro de 2020

\begin{abstract}
The subjects involved in the activity do not always perceive the benefits from tourism equally. Guests and hosts occupy and dispute the same territory, but not necessarily in a balanced way. The role of the State can be to reconcile these interests by ordering urban space so that everyone benefits. Public policies that extrapolate statistical and economic issues and incorporate aspects of urban planning become fundamental in this process; otherwise, the city will have territories "consumed" by the practice of tourism. It is in this direction that urban hospitality and urban legislation come together. This work has as main objective to explore how certain urbanistic parameters, inserted in the Master Plans, are able to guarantee the condition of a hospitable city. The partial results of the ongoing post-doctoral research that analyzes the Master Plans of the "Estâncias Balneárias of São Paulo" are used as a basis. Documentary and bibliographic researches are used as a method, based on the texts, maps and tables of the referred laws.
\end{abstract}

Keywords: Public policies. Urban Hospitality. Public Space.

\section{La importancia de los parámetros de planificación urbana para la generación de ciudades hospitalarias}

\begin{abstract}
Resumen
Los beneficios derivados del turismo no siempre son percibidos igualmente por los sujetos involucrados en la actividad. Los huéspedes y los anfitriones ocupan y disputan el mismo territorio, pero no necesariamente de manera equilibrada. Puede ser función del Estado conciliar estos intereses ordenando el espacio urbano para que todos se beneficien. Las políticas públicas que extrapolan cuestiones estadísticas y económicas e incorporan aspectos de la planificación urbana se vuelven fundamentales en este proceso, de lo contrario la ciudad tendrá territorios "consumidos" por la práctica del turismo. Es en esta dirección que la hospitalidad urbana y la legislación urbana se unen. Este trabajo tiene como objetivo principal explorar cómo ciertos parámetros de planificación urbana, insertados en los Planes Maestros, pueden garantizar la condición de una ciudad hospitalaria. Los resultados parciales de la investigación postdoctoral en curso, que analiza los Planes Maestros de las "Estâncias Balneárias de São Paulo" se utilizan como base. Como método, se utiliza la investigación documental y bibliográfica basada en los textos, mapas y tablas de las leyes referidas.
\end{abstract}

Palabras clave: Políticas públicas. Hospitalidad urbana. Espacio publico. 


\section{Problemática e objetivos}

A atividade turística é uma prática sócioespacial que envolve sujeitos sociais de várias ordens e com expectativas diferentes (BARRIOS, 1986). Moradores, turistas, comerciantes, empresários e poder público ocupam e disputam o mesmo território, mas não necessariamente de forma equilibrada. Para Paiva (2016, p. 44):

A atividade turística compõe uma das principais práticas sócioespaciais da contemporaneidade que interfere no processo de urbanização, na medida em que reforça as transformações funcionais, técnicas, estruturais, formais e estéticas do território e da cidade.

Ora, se o espaço desempenha o papel de reprodutor material da organização social, cabe ao poder público conciliar esses interesses direcionando a expansão urbana e ordenando o território para que todos se beneficiem (CRUZ, 1999). Afinal, a cidade deve proporcionar lazer primeiro para seus moradores e, posteriormente, para os turistas. Ao afirmar que o centro do processo é sempre o turista, Camargo (2004) questiona a maneira pela qual se mede o sucesso da atividade turística. Segundo autor, a EMBRATUR (Instituto Brasileiro de Turismo) contabiliza ganhos e perdas tanto em termos financeiros (medindo o sucesso do turismo por quilômetros viajados e dólares gastos), quanto em termos econômicos (contabilizando postos de trabalho abertos, mesmo se tratando de empregos precários e mal remunerados).

Parte-se do entendimento que o enfoque dado para a promoção da atividade turística deve extrapolar as questões de ordem estatística e econômica e abranger aspectos de ordem urbanística (SEVERINI \& PANOSSO NETTO, 2019). Ganha força nesse cenário a hospitalidade urbana e o planejamento. Para Camargo (2004), o campo do planejamento é o único campo dos estudos turísticos que dá espaço à hospitalidade, que, para o autor deveria ser um dia chamado de "planejamento da hospitalidade".

A condição de cidade hospitaleira está atrelada a aspectos físicos do espaço urbano que visam promover o acolhimento e o bem-estar não só de turistas, mas também, e essencialmente, de moradores (FERRAZ, 2013). Esses aspectos estão vinculados ao desenho urbano. Diversamente do que ocorre nas outras esferas da hospitalidade $^{1}$, na hospitalidade urbana o espaço encarregado para sediar as relações sociais entre hóspede e anfitrião não é um espaço privado, mas sim o espaço público. Isso altera completamente a compreensão de quem são e quais são as responsabilidades dos agentes da hospitalidade urbana (SEVERINI, 2013).

Por um lado, o hóspede urbano se divide entre morador e turista, pois todos consomem ou vivem a experiência da cidade. Para Severini $(2013$, p.6) o morador quando "visita um novo museu, um centro cultural recém-inaugurado, um centro de exposições, uma praça, uma avenida reformada, se torna um turista em sua própria cidade". Do outro lado, a figura do anfitrião urbano é compartilhada pelo gestor público e por todos aqueles que usufruem do espaço público compartilhando a tarefa de zelar pelo espaço da cidade (SEVERINI \& VARGAS, 2017).

\footnotetext{
${ }^{1}$ Esta pesquisa utiliza a classificação de Camargo (2003) que entende que a hospitalidade enquanto instância social e se desenvolve em quatro categorias: doméstica, pública, comercial e virtual. Vale mencionar que a hospitalidade urbana é derivada da hospitalidade pública.
} 
Este artigo tem como objetivo central abordar como certos parâmetros urbanísticos, tidos como essenciais para a geração de cidades hospitaleiras, podem ser incorporados em Planos Diretores de cidades turísticas para garantir que o usufruto dos atrativos turísticos beneficie a todos, moradores e turistas. Tida como a lei municipal que define as diretrizes de crescimento da cidade a partir de vários aspectos, como físicos, econômicos, sociais, ambientais e urbanísticos, o Plano Diretor passou a ser obrigatório em "cidades integrantes de áreas de especial interesse turístico"2 desde 2001. Para dar conta de atender esse objetivo, utiliza-se como base os dados da pesquisa em andamento intitulada "Cidades paulistas litorâneas, cidades hospitaleiras?"3.

$\mathrm{O}$ artigo foi dividido em três partes. Em primeiro lugar apresenta-se o recorte espacial da pesquisa e explora-se quais elementos urbanos reúnem os códigos da cidade hospitaleira. Em seguida, são apresentados os resultados parciais da pesquisa explorando como parâmetros urbanísticos básicos podem ajudar no processo de qualificação do espaço público. Por fim, são esboçadas considerações finais visando subsidiar tomadas de decisão no âmbito das políticas públicas de desenvolvimento urbano para cidades turísticas.

\section{Recorte espacial e metodologia}

Fugindo à regra dos estados brasileiros, que, em sua maioria utilizam a metodologia do Programa de Regionalização do Turismo e o Mapa do Turismo ${ }^{4}$ para decidir quais são as cidades turísticas, o governo do Estado de São Paulo exige a elaboração de lei para cada cidade (turística) após observadas as condições e atendidos os requisitos mínimos estabelecidos na Lei 1.261/15. Por outro lado, dentre essas condições e pré-requisitos não estão nem a exigência na elaboração de Planos Diretores tampouco a observação de aspectos referentes a infraestrutura urbana existente (SEVERINI \& PANOSSO NETTO, 2019).

As cidades turísticas paulistas são classificadas em duas categorias: Estâncias Turísticas (balneárias, hidrominerais, turísticas e climáticas) e Municípios de Interesse Turístico (MIT).

A pesquisa em andamento tem como recorte espacial os Planos Diretores das Estâncias Balneárias do Estado de São Paulo. Para a elaboração deste artigo foram analisados os Planos Diretores de oito cidades do litoral paulista. São elas: Santos, Guarujá, São Vicente, Praia Grande, Mongaguá, Itanhaém, Peruíbe e Ilhabela.

Utilizou-se como método a pesquisa documental. Os dados primários analisados são referentes aos textos, mapas, quadros e tabelas dos Planos Diretores em questão.

\footnotetext{
2 O Estatuto da Cidade exige a elaboração de Plano Diretor em quatro situações: (a) cidades com mais de vinte mil habitantes; (b) cidades integrantes de regiões metropolitanas e/ou aglomerações urbanas; (c) cidades integrantes de áreas de especial interesse turístico e; (d) cidades inseridas na área de influência de grandes empreendimentos com grande impacto ambiental.

3 A pesquisa trata-se do pós-doutoramento em Turismo de Valéria Ferraz Severini que é desenvolvida no Programa de Pós-Graduação em Turismo da Escola de Artes, Ciências e Humanidades da Universidade de São Paulo (EACH-USP), sob a supervisão de Alexandre Panosso Netto.

4 O Programa de Regionalização do Turismo é um programa do governo federal implantado pelo Ministério do Turismo em 2013. Tem como objetivo "subsidiar a estruturação e qualificação dessas regiões, buscando fortalecer a identidade local". Como parte do Programa, foi elaborado o Mapa do Turismo Brasileiro - instrumento que guia a atuação dos Órgãos Estaduais de Turismo no desenvolvimento de políticas públicas que orientem os investimentos para cada região.
} 


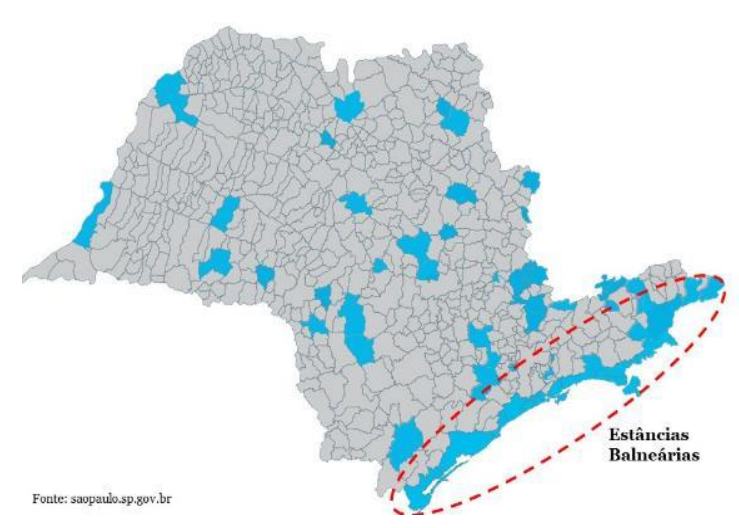

Figura 1 - Mapa com as Estâncias Turísticas do Estado de São Paulo.

Fonte: saopaulo.sp.gob.br (acessado em 2019).

\subsection{Categorias de análise da cidade hospitaleira}

A partir da regulamentação do Estatuto da Cidade (Lei 10.257/2001), as leis de desenvolvimento urbano passaram a ter novos instrumentos urbanísticos capazes de interferir significativamente na urbanização brasileira. Novos parâmetros de desenho urbano passaram a fazer parte dos Planos Diretores e das Leis de Zoneamento. Com isso, o anfitrião urbano, representado na figura do gestor público, ganhou novas ferramentas para interferir no parcelamento, uso e ocupação do solo, qualificando o espaço público e estabelecendo regras mais rígidas para as construções em âmbito privado.

Todavia, quais são os aspectos urbanos característicos da cidade hospitaleira? Esta pesquisa toma como base os estudos de dois autores brasileiros que se propuseram a identificá-los. São eles: Lucio Grinover $(2007 ; 2016)$ e Valéria Ferraz (2013). Para Ferraz (2013), a hospitalidade urbana é decorrente de uma somatória de sensações oriundas de atributos tangíveis (físicos e mensuráveis) e de atributos intangíveis (subjetivos e imensuráveis). A autora concentra seus estudos nos atributos tangíveis, pois só eles é que podem ser classificados, mapeados e implementados pelo gestor público. Utilizando como base os estudos de Grinover (2007) somado a uma ampla bibliografia sobre paisagem e desenho urbanos, Ferraz (2013) estabeleceu quatro "atributos espaciais de hospitalidade urbana": diversidade, permeabilidade, legibilidade e conforto. Cada categoria é capaz de avaliar (e medir) uma série de características físicas relacionadas a sensação de acolhimento e bem-estar no espaço urbano (SEVERINI, 2016).

A diversidade identifica a mistura de usos e atividades de um trecho urbano, assim como a variedade de espaços públicos e espaços privados de uso público. A permeabilidade identifica a capacidade de um lugar em se deixar permear no sentido físico, por meio de quadras curtas ou espaços internos de edifícios, e no sentido visual, por meio de elementos de transparência. A legibilidade identifica elementos visuais referenciais, como edifícios, marcos e monumentos, e identifica a heterogeneidade ou monotonia arquitetônica. O conforto identifica espaços confortáveis no sentido físico e ambiental, através de elementos arquitetônicos e paisagísticos.

Ao associar os estudos de hospitalidade urbana ao sistema da dádiva de Marcel Mauss (2003), Ferraz (2013) ressalta a importância das ações de cidadania para a geração da cidade hospitaleira. Segundo a autora, a tríplice obrigação do 
dar-receber-retribuir está presente também na hospitalidade urbana. Afinal, ao receber as benfeitorias ofertadas pelo anfitrião urbano, o hóspede irá retribuir por meio de ações de cidadania (SEVERINI \& VARGAS, 2017). Isso se torna tão verdadeiro, que Grinover (2016) em sua última obra acaba transformando a cidadania em uma nova dimensão da hospitalidade urbana ${ }^{5}$. Para este autor (2016, p.1132), "a cidadania vive e respira no espaço público" e é aí que as competências éticas estão colocadas à prova. As ações de cidadania estão presentes nas formas de incentivo à participação popular na elaboração e implementação de políticas públicas de desenvolvimento urbano. Isso pode proporcionar a liberação de uma quantidade fantástica de energias transformadoras com que a gestão burocrática e tradicional dos processos administrativos jamais sonharia (GRINOVER, 2016).

Diante disso, a pesquisa adotou os estudos de ambos autores e criou cinco "categorias de análise da cidade hospitaleira". São elas: diversidade, permeabilidade, legibilidade, conforto e cidadania. Essas categorias foram utilizadas para identificar como e onde os conceitos de hospitalidade urbana foram incorporados nos Planos Diretores das cidades litorâneas paulistas.

Após leitura detalhada dos Planos Diretores foram identificadas as diretrizes em função de sua proximidade às categorias de análise da cidade hospitaleira. Em seguida, essas diretrizes foram organizadas e setorizadas em planilhas a fim de identificar quais ações tem a capacidade de estimular acolhimento e bem-estar no espaço urbano. A seguir, apresenta-se uma parte de uma das planilhas elaborada com base na "categoria de análise da cidade hospitaleira" diversidade.

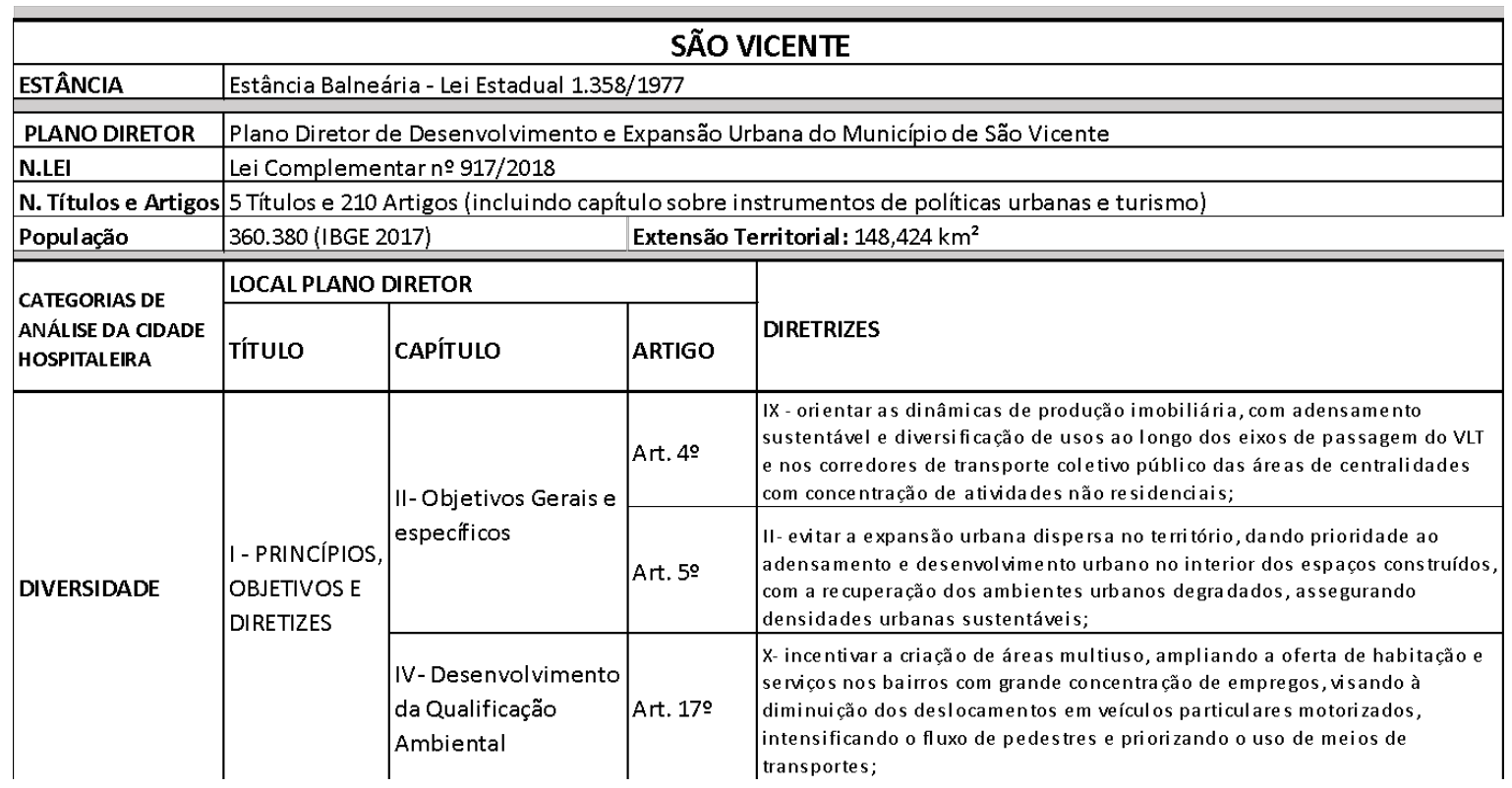

Figura 2 - Diretrizes da categoria diversidade identificadas no Plano Diretor de São Vicente.

Fonte: autores, 2020.

\footnotetext{
5 Para Grinover (2007), uma cidade é hospitaleira em função da coexistência de três dimensões fundamentais: acessibilidade, legibilidade e identidade. Em sua última obra (2016), o autor expandiu a dimensão acessibilidade para mobilidade e acrescentou a dimensão cidadania.
} 


\title{
3 Resultados parciais
}

A seguir serão apresentados os resultados parciais da pesquisa em andamento apontando como as "categorias de análise da cidade hospitaleira" foram incorporadas nos Planos Diretores das oito cidades analisadas. A sigla PD será utilizada para representar Plano Diretor.

\subsection{Diversidade}

A categoria diversidade está presente em todos os Planos Diretores analisados, em geral nos capítulos referentes ao Ordenamento Territorial. Ela se manifesta principalmente nas diretrizes que visam incentivar o adensamento construtivo e populacional em áreas dotadas de infraestrutura. Destacam-se aqui os Planos Diretores de Santos e São Vicente que estimulam esse adensamento junto as quadras próximas ao VLT - Veículo Leve sobre Trilhos. O Artigo 17 do PD de São Vicente visa:

\begin{abstract}
Incentivar a criação de áreas multiuso, ampliando a oferta de habitação e serviços nos bairros com grande concentração de empregos, visando à diminuição dos deslocamentos em veículos particulares motorizados, intensificando o fluxo de pedestres e priorizando o uso de meios de transportes.
\end{abstract}

Para além do incentivo ao zoneamento de uso misto, os parâmetros urbanísticos referentes ao tipo de ocupação do solo Coeficiente de Aproveitamento (CA), Taxa de Ocupação (TO) e Recuos Mínimos também são essenciais para a geração de diversidade num determinado trecho urbano. Quanto maior for o CA e o TO de uma determinada zona, mais adensada construtivamente ela será e, em tese, maior será o adensamento populacional. Destaca-se aqui os Planos Diretores de Guarujá, Praia Grande, Peruíbe e Ilhabela que definem alguns desses parâmetros.

O Artigo 176 do PD de Peruíbe define os índices de CA. São eles: CA mínimo de 0,15 , CA básico de 1 e CA máximo de 3. Para as "zonas de alta densidade" caracterizadas pelo alto índice de aproveitamento do solo, o Artigo 96 do PD do Guarujá estipula para o CA mínimo de 0,1 , CA básico de 4 e CA máximo de 5 .

Já o PD de Peruíbe não estabelece valores para os parâmetros urbanísticos acima citados, mas o Artigo 111 define que na "Macrozona Turística de Sol e Praia" certos instrumentos da política urbana (chamados no PD de "instrumentos de ordenação do desenvolvimento do território") sejam aplicados no intuito de gerar adensamento, entre eles: Operações Urbanas Consorciadas, Outorga Onerosa do Direito de Construir e Área Receptora de Potencial Construtivo.

A definição desses parâmetros urbanísticos delineia o tipo de ocupação desejada para cada trecho urbano. A proposta de aumentar o CA e o TO, e flexibilizar os Recuos, vai ao encontro da ideia de "racionalização do território", o que parece ser o ideal para o poder público. Afinal, quanto mais adensada (do ponto de vista populacional e construtivo) for uma cidade mais fácil será sua governabilidade. Contudo, as políticas públicas de desenvolvimento urbano de certas cidades litorâneas parecem não seguir esse modelo e estimulam a criação 
ou a manutenção de bairros de veraneio, que são o oposto da ideia de otimização/racionalização do território. Dotados de calçadas, ruas bem pavimentadas, postes de iluminação e sinalização e rede de água, esgoto e telefonia instalados, esses bairros ficam ocupados apenas na alta estação e/ou feriados e permanecem vazios no resto do ano, tornando o lugar inseguro e caro para ser mantido pelo poder público.

A seguir dois exemplos de como o território pode ser ocupado.

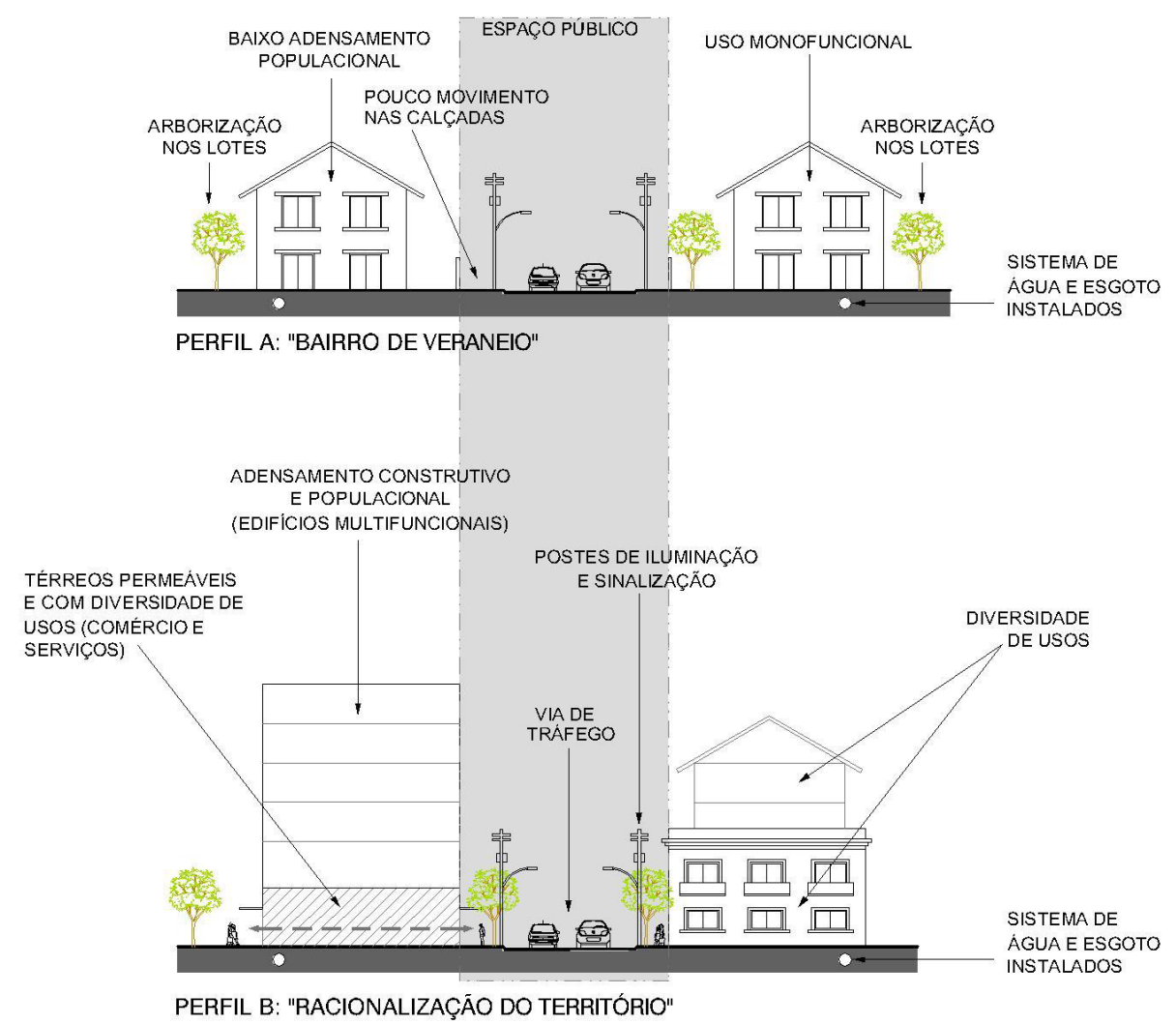

Figura 3 - Croqui com dois tipos de ocupação do território urbano: bairros de veraneio e bairros com adensamento construtivo.

Fonte: autores, 2020.

Porém, muitos Planos Diretores acabam caindo numa armadilha. Em suas diretrizes iniciais, incorporadas nos capítulos referente aos Conceitos, Princípios e Objetivos, alguns planos incentivam a racionalização do território a fim de evitar a ociosidade de certos trechos urbanos e a especulação imobiliária. É o caso do Artigo 10 do PD de Mongaguá que visa "organizar o uso e a ocupação do solo no território do município e, em particular, em sua área urbana, visando evitar a retenção especulativa do imóvel urbano, que resulte sua subutilização ou não utilização". Mas o mesmo PD estabelece no Artigo 22 "preservar e proteger as áreas de uso estritamente residencial". O mesmo ocorre no PD do Guarujá. De um lado visa "combater a especulação imobiliária da qual resulte a subutilização ou não utilização de imóveis urbanos" (Artigo 10), e de outro lado cria "zonas de baixa densidade" em áreas junto a orla marítima, como a Praia da Enseada. Os Artigo 105 e 106 do PD do Guarujá definem para essas zonas parâmetros urbanísticos que incentivam o uso monofuncional (estritamente residencial) e o baixo adensamento populacional, 
como: Coeficiente de Aproveitamento (CA) mínimo de 0,1 ; básico de 1 e máximo de 1,2; Gabarito máximo de 11 (onze) metros e Recuo frontal de 5 metros.

Ora, se a intenção é otimizar o território, evitando sua ociosidade e desestimulando a especulação imobiliária, como é possível criar zonas de baixa densidade em áreas dotadas de infraestrutura urbana? O que se quer é a otimização do território ou a reserva de áreas próximas a praia para uso estritamente residencial e temporário?

\subsection{PERMEABILIDADE}

Diretrizes de permeabilidade podem ser incorporadas em capítulos específicos sobre Parcelamento do Solo ou Mobilidade Urbana (dentro de Políticas Setoriais). Os Planos Diretores de Mongaguá e Itanhaém, por exemplo, incentivam a abertura de novas vias e passarelas sobre a Rodovia Padre Manoel da Nóbrega - via que "corta" esses municípios e nitidamente segrega o território entre as porções de terra destinadas à população local (trecho entre a rodovia e a serra) e ao turismo (trecho entre a rodovia e a orla marítima. O Artigo 65 do PD de Mongaguá visa "facilitar a interligação entre as áreas residenciais e as áreas ao longo da orla marítima, minimizando o impacto do tráfego de passagem na rodovia e contribuindo para a redução de acidentes". Contudo, nenhum dos Planos já deixa indicado a localização dessas futuras intervenções.

Mas as diretrizes relacionadas à permeabilidade vão além de intervenções viárias. A permeabilidade pode estar presente em regras urbanísticas relacionadas ao "remembramento de lote" e às "dimensões mínimas e máximas" dos lotes. Ao restringir o valor em $\mathrm{m}^{2}$ dos lotes, o poder público pode evitar que grandes resorts sejam implantados à beira-mar impedindo o acesso da população à faixa de areia (ver Figura 4). Essa situação se agrava em cidades que não possuem uma avenida à beira-mar e em locais que possuem litorais "recortados", como algumas praias do Guarujá e de llhabela. A configuração espacial das cidades de Santos e São Vicente e do litoral sul (Praia Grande, Mongaguá, Itanhaém e Peruíbe) facilitam o acesso à faixa de areia.

A implantação do "Sofitel Guarujá Jequitimar" exemplifica essa situação. Implantado em um terreno à beira-mar de cerca de $80 \mathrm{mil} \mathrm{m}^{2}$, o hotel ocupa uma área que poderia acomodar 7 (sete) quadras de tamanho normal e gerar mais movimento e conexões viárias no local. As quadras do mesmo bairro, a Praia de Pernambuco, tem aproximadamente $75 \times 150 \mathrm{~m}$. A dificuldade de acesso à praia só não é pior pois a estrutura da malha viária do entorno permite o acesso à faixa de areia através de ruas laterais (Figura 4).
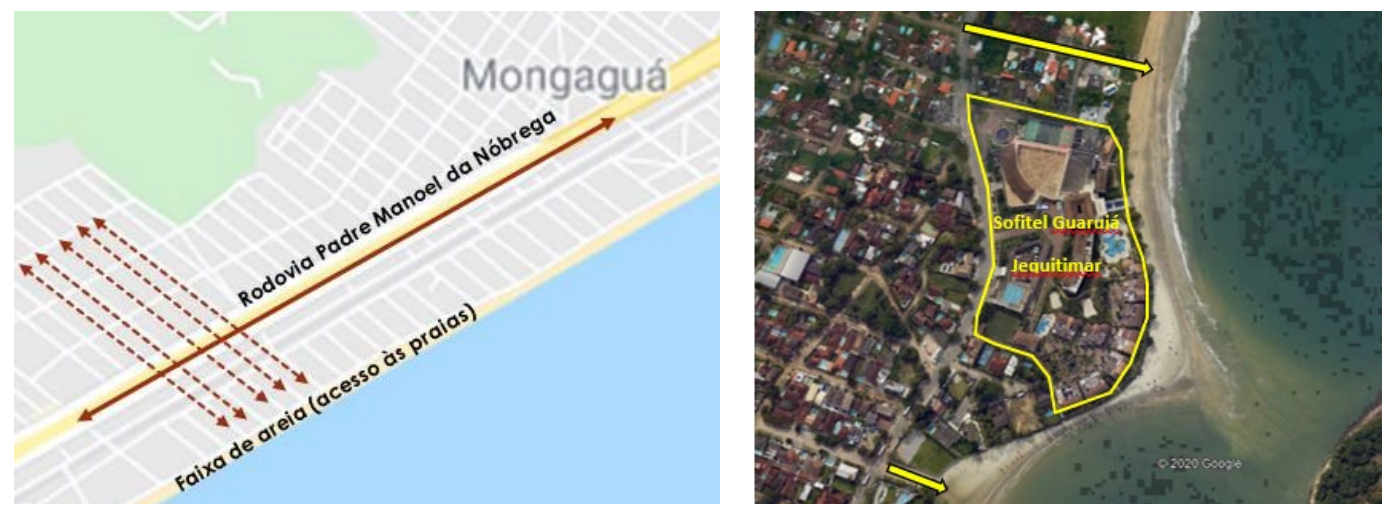
Figura 4 - Trecho da malha viária de Mongaguá e implantação do "Sofitel Guarujá Jequitimar" (croquis realizados sobre imagem do Google Maps e Google Earth).

Fonte: autores, 2020.

No que tange à permeabilidade visual, algumas regras urbanísticas podem ser inseridas nos capítulos sobre Ordenamento Territorial, entre elas "limite de vedação da testada do lote" e "fachada ativa"6. Essas regras incentivam transparência e abertura nas fachadas (muros baixos, gradis e vitrines) possibilitando um contato visual com o lado interno da edificação e contribuindo para a sensação de segurança. A obrigatoriedade em implementar interfaces transparentes ou vazadas, ajuda a tornar o bairro um local mais acolhedor gerando uma sensação de "copresença", ou seja, a presença de pessoas no espaço público pressupõe a presença de outros indivíduos engajados (ou não) em atividade compartilhada.

O Plano Diretor de llhabela é o único que contém uma diretriz específica que incentiva a implantação de fachadas transparentes. O Artigo 177 determina:

Restringir a altura dos muros a serem edificados nas áreas de interesse turístico paisagístico: a base de alvenaria deverá ter altura máxima de $0,5 \mathrm{~m}$, e o restante constituído de materiais que não obstruam a visibilidade e circulação de ar.

Quando a interface entre espaço público e espaço privado é transparente, a sensação é de acolhimento e bem-estar. Mas quando essa interface é opaca o desconforto do pedestre é inevitável. Sendo que essa última situação é a mais comum nos bairros de veraneio, que são dotados de casas fechadas com muros altos e opacos que tornam o lugar hostil e inseguro para o pedestre (Figura 5).

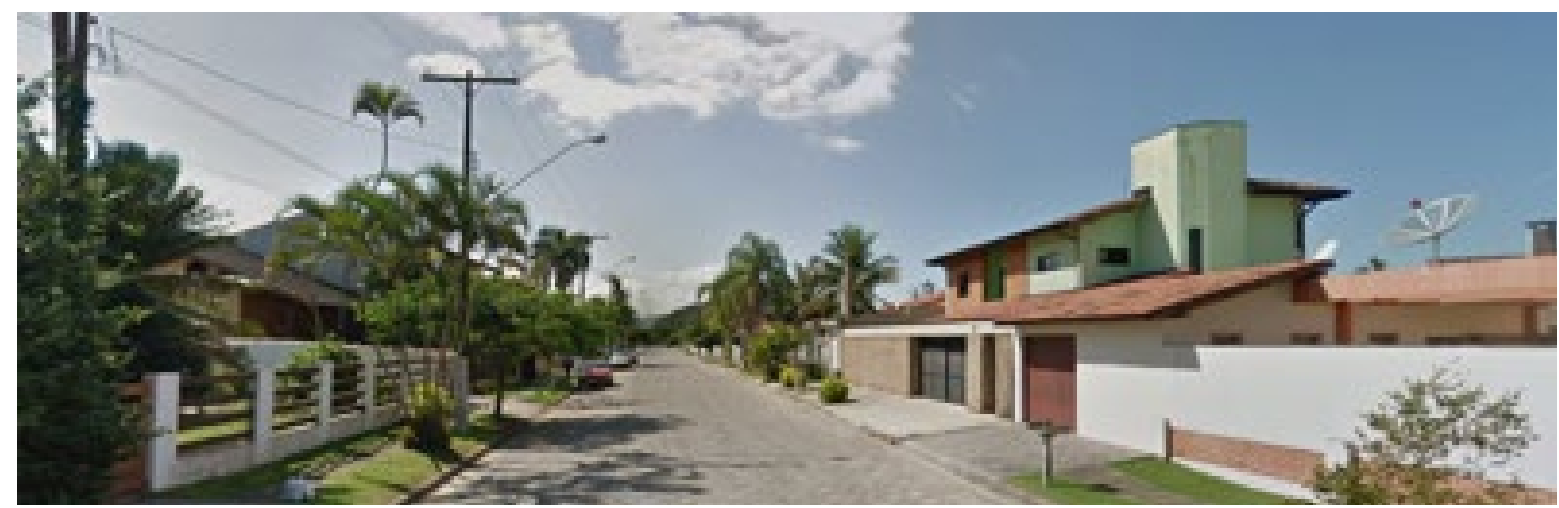

Figura 5 - Típica ocupação nos bairros de veraneio de cidades litorâneas. Acima um exemplo de interfaces transparentes (à esquerda) e interfaces opacas (à direita), na Praia dos Sonhos, Itanhém.

Fonte: autores, 2020.

\subsection{LEGIBILIDADE}

A incorporação da categoria legibilidade pode ser percebida nos capítulos específicos sobre Paisagem Urbana e Patrimônio Cultural, como ocorre os Planos Diretores do Guarujá, São Vicente e Santos. Cabe ao poder público municipal

\footnotetext{
${ }^{6}$ Inseridos no item Parâmetros de Ocupação do Solo, esses dois instrumentos urbanísticos estão previstos na Lei de Parcelamento, Uso e Ocupação do Solo do Município de São Paulo (Lei 16.402/16).
} 
garantir o direito do cidadão à fruição da paisagem pela identificação, leitura e apreensão dos elementos urbanos. Para tanto, é preciso "garantir a qualidade ambiental do espaço público, assegurando a harmonia entre os diversos elementos que compõem a paisagem urbana, evitando a poluição visual" - como diz o Artigo 19 do PD do Guarujá.

Estímulos à permanência de ícones ou edifícios de valor cultural ajudam a manter a história do local e facilitam a leitura da cidade. As pessoas, sejam elas turistas ou moradores, utilizam essas referências visuais para se localizarem na cidade. O Artigo 45 do PD da Praia Grande designa ao poder público municipal a tarefa de assegurar a proteção do patrimônio cultural de expressão local. Para respaldar essa ação, o mesmo Artigo estabelece que Poder Executivo crie o Conselho Municipal de Preservação do Patrimônio Histórico, Artístico e Cultural.

Já o Artigo 40 do PD de Itanhaém estabelece o "Setor de Interesse Cultural" que engloba os monumentos tombados e os imóveis de interesse do patrimônio histórico e cultural. A criação de "setores" (ou áreas de especial interesse) para as áreas dotadas de patrimônio é de extrema importância para que certos instrumentos da política urbana sejam aplicados no futuro, como a "transferência de potencial construtivo". Previsto no Estatuto da Cidade, esse instrumento permite transferir os potenciais construtivos do lote onde está sediado um bem tombado, e que tem restrições urbanísticas, para outro lote. A "transferência do potencial construtivo" para outro lote com capacidade de infraestrutura adensável é uma das soluções utilizadas para beneficiar o proprietário do imóvel que sofreu restrição. Essa estratégia é reforçada no Artigo 69 do mesmo PD de Itanhaém:

Instituir compensação financeira dos proprietários de imóveis protegidos, através, por exemplo, da permuta e transferência de potencial construtivo ou de instrumentos fiscais, como isenção de tributos, como forma de incentivo financeiro ao proprietário, para que este proceda à restauração e faça a manutenção da edificação, com orientação e acompanhamento do Conselho Municipal de Defesa do Patrimônio Histórico, Artístico e Cultural, desde que não tenha deliberadamente dado causa à sua deterioração;

Aqui cabe mencionar um importante parâmetro urbanístico de ocupação do solo que também deve ser observado nas cidades turísticas. Trata-se do "Gabarito", que determina a altura máxima da edificação, em metros ou em número de pavimentos. Sem esse controle, a cidade pode "engolir" seus marcos urbanos e a própria paisagem local. A Figura 6 é um exemplo de como essa falta de controle pode prejudicar a legibilidade do local e o turismo. Situado entre as praias da Enseada e Pitangueiras, o "Mirante da Campina" - implantado no Morro do Maluf, é um dos pontos turísticos da cidade. Mas sua vista está comprometida. Lá de cima só é possível avistar a Praia da Enseada, pois a vista para a Praia de Pitangueiras está impedida pelos prédios altos ali implementados. 


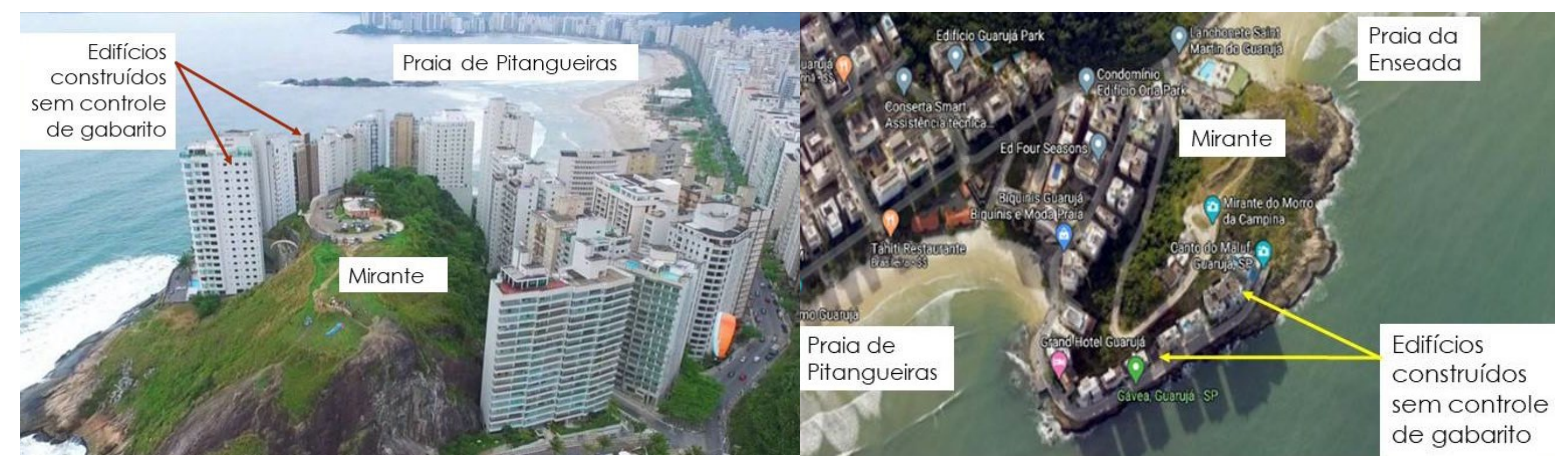

Figura 6 - Vista comprometida do Mirante da Campina, Guarujá (imagens obtidas no Google Earth).

Fonte: http://cyberspaceandtime.com/kTo9F5tEp48.video+related

$\mathrm{Na}$ intenção de evitar algo parecido, o Artigo 50 do PD de Itanhaém visa:

Manter gabaritos crescentes no sentido praia-serra e estabelecer limite máximo de pavimentos para cada trecho da orla da praia, definindo de acordo com suas características geológicas, distância e desnível em relação à faixa de areia, em especial para a praia do Centro.

\subsection{CONFORTO}

A oferta de espaços confortáveis no espaço público depende muito do poder público. Em tese, é o Estado que pode interferir no espaço em prol do bem comum. Nesse sentido, percebe-se a incorporação da categoria conforto em diretrizes relacionadas a requalificação de calçadas, implantação de parques e áreas verdes, arborização viária e implantação de mobiliário urbano. Essas ações estão em capítulos relacionados a Políticas Setoriais, Mobiliário Urbano e Estrutura Urbana e Ambiental.

O Artigo 18 do PD de Mongaguá visa "promover programas de arborização nas vias públicas e incentivar programas similares nas propriedades privadas". Já o Artigo 88 do PD da Praia Grande visa:

Promover segurança e conforto ao deslocamento de pedestres por meio da requalificação e ampliação da rede de calçadas e demais componentes do sistema de circulação de pedestres, tais como travessias, transposições e sinalização específica, bem como da sua infraestrutura complementar, tais como arborização urbana, mobiliário urbano e iluminação pública.

O incentivo à implantação de mobiliário urbano pode ser percebido no Artigo 54 do PD de Itanhaém que visa:

Elaborar regulamento específico para a instalação de equipamentos de mobiliário urbano em geral, contendo no mínimo: I) quanto à instalação de placas, posteamento e arborização nos passeios públicos, que estejam todos alinhados junto à guia, ocupando no máximo o primeiro terço da largura do passeio; II) padronização do mobiliário urbano em locais de interesse histórico, cultural ou turístico; III) regulamentação com o tipo do revestimento dos passeios públicos, com proibição de padrões que dificultem a locomoção de pessoas com mobilidade reduzida ou sejam escorregadios; 
O jardim das praias de Santos e São Vicente acaba sendo uma referência para a região. Dotado de ciclovias, bancos para sentar, lixeiras e chuveiros, esse espaço público pode ser visto como a sala de estar dessas cidades (Ver Figura 7). Objetivo reforçado pelo Artigo 128 do PD de Santos que estabelece que as praias "deverão receber tratamentos paisagístico e estético, adequados e permanentes, preservando suas características de espaços dinâmicos".
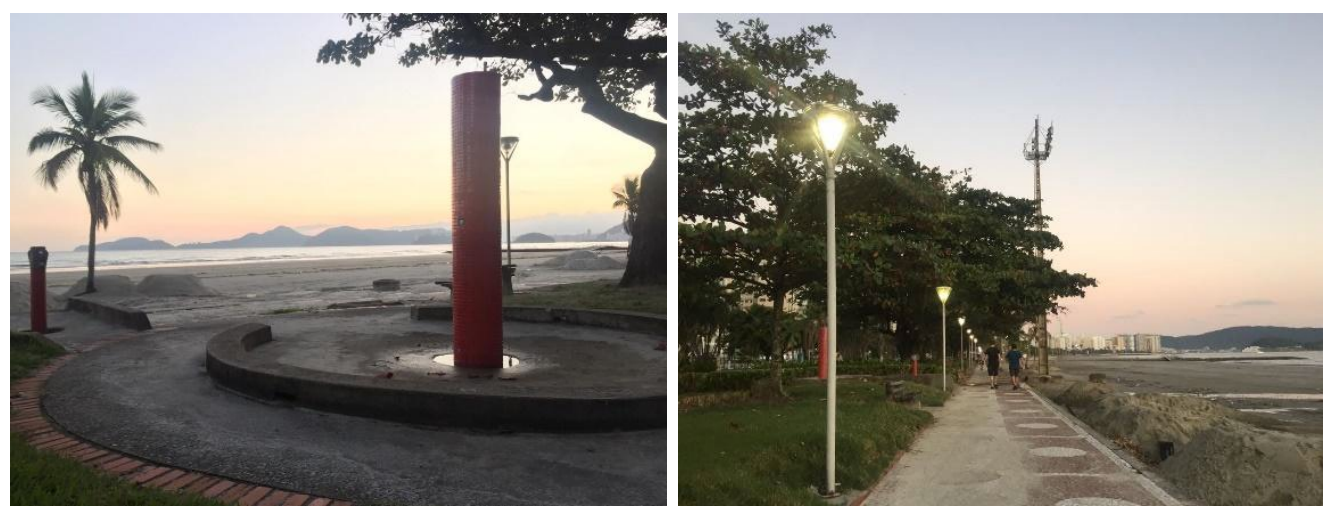

Figura 7 - Jardim das praias de Santos, com chuveiros, iluminação e calçadão.

Fonte: autores, 2020.

Mas o conforto sentido no espaço público também está relacionado, em certa medida, com as construções em âmbito privado. O Gabarito, regra urbanística já mencionada no item anterior, é um exemplo de como os edifícios podem interferir no conforto do espaço público. O croqui abaixo exemplifica uma situação onde os prédios situados à beira mar foram construídos sem controle de gabarito, gerando áreas de sombra na faixa de areia. Essa situação pode prejudicar o turismo. Destaca-se aqui o Artigo 14 do PD do Guarujá que visa "garantir a insolação das praias, impedindo intervenções urbanas e edilícias que provoquem 0 sombreamento das áreas públicas de banho, excetuando-se as áreas de alta densidade, já edificadas em seus conjuntos".

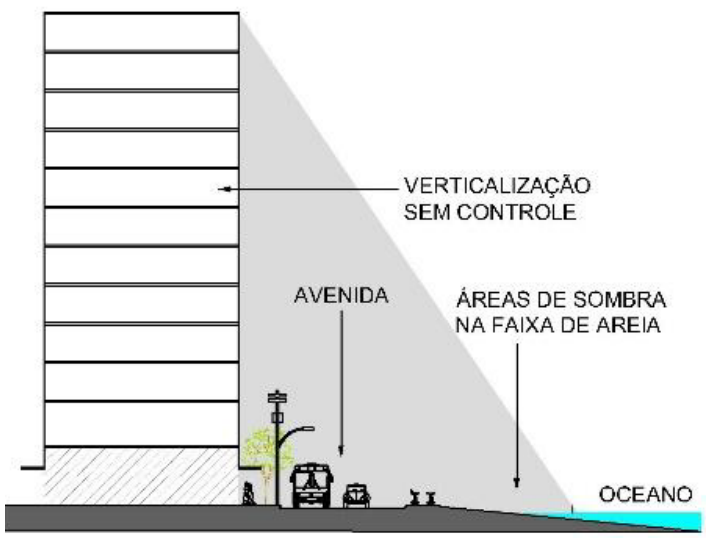

Figura 8 - Croqui que simula a sombra dos prédios na faixa de areia.

Fonte: autores, 2020.

Vale a pena mencionar que adensamento não significa verticalização. Ao combinar certas regras urbanísticas, como aumentar o valor do CA e do TO e 
diminuir os recuos, é possível ter um controle maior do gabarito e gerar adensamento construtivo e populacional.

Obrigar a implementação de um sistema de saneamento próprio em loteamentos particulares e criar restrições para jogar o esgoto na rede pública sem tratamento é outra ação que pode ser estimulada para gerar conforto no espaço público. Isso pode ser percebido no Artigo 50 do PD de Ilhabela que visa:

\begin{abstract}
Vedar a instalação de qualquer empreendimento ou equipamento urbano, mesmo que de interesse público que lance efluentes nos corpos d'água. $O$ lançamento de esgotos e efluentes não poderá provocar euforização, poluição em geral, aumento de turbidez ou assoreamento do corpo de água que o receber.
\end{abstract}

\title{
3.5 CIDADANIA
}

As diretrizes que incorporam a categoria cidadania estão geralmente inseridas nos capítulos sobre Gestão do Sistema Municipal de Planejamento Urbano. Para além das diretrizes que visam assegurar a participação da população em todas as fases do processo de gestão democrática da política urbana (como audiências públicas, assembleias territoriais, conferência da cidade, plebiscito e referendo popular, conselhos de políticas públicas setoriais e iniciativa popular de projetos de lei, de planos, programas e projetos de desenvolvimento urbano - como faz o Artigo 76 do PD de Peruíbe), a categoria cidadania também pode estar presente em diretrizes que estimulem a parceria público privada. O Artigo 30 do PD da Praia Grande incentiva o" fornecimento de projetos padrão, cesta básica e assistência técnica gratuita" e o Artigo 98 visa:

\begin{abstract}
Promover a parceria com o setor privado em programas de desenvolvimento urbano e habitacional, tendo em vista as restrições orçamentárias de Município face às crescentes demandas decorrentes do processo de desenvolvimento regional.
\end{abstract}

Os Planos Diretores de Santos e São Vicente também estimulam esse tipo de parceria. O Artigo 64 do PD de São Vicente propõe "utilizar estudos e levantamentos realizados por instituições de ensino ou pesquisa acadêmica devidamente reconhecidos pelo MEC ou cadastrado no CNPq para identificar se o imóvel está por mais de 1 (um) ano desocupado". Já o Artigo 68 do PD de Santos permite:

Utilizar bancos de dados específicos elaborados pelo Poder Público municipal, autarquia, empresa pública municipal e empresas concessionárias de serviços públicos para identificar se o imóvel está por mais de 1 (um) ano desocupado.

Essas duas diretrizes estão vinculadas ao instrumento de política urbana "IPTU Progressivo no Tempo", que visa combater a ociosidade de imóveis situados em regiões da cidade dotadas de infraestrutura urbana. Esse instrumento estimula a racionalização do território e vai ao encontro dos objetivos da categoria diversidade. 
Nos capítulos de Políticas Setoriais também é possível encontrar diretrizes de cidadania. Em Políticas de Habitação, o destaque fica por conta do Artigo 20 do PD do Guarujá estimula a realização de parcerias com universidades e institutos de pesquisa para o desenvolvimento de alternativas de menor custo e maior qualidade e produtividade das edificações residenciais. E, em Políticas Culturais, o Artigo 39 do PD de llhabela propõe o tombamento de bens imóveis de valor histórico a partir de estudos realizados em parceria entre o poder municipal e o CONDEPHAAT.

\section{Considerações finais}

Os resultados parciais da pesquisa reforçam a importância da definição de certos parâmetros urbanísticos nos Planos Diretores de cidades turísticas. Diante da forte pressão por parte dos empresários do setor turístico e imobiliário sobre o território urbano, sem essas definições essas cidades correm o risco de serem ocupadas de forma desigual acarretando uma reconfiguração espacial que não necessariamente dialoga com a infraestrutura local, comprometendo a qualidade de vida dos moradores e alterando a paisagem urbana local. Isso remete a necessidade de planejamento e reforça o papel do Estado, dando a ele o poder de decidir, junto com a sociedade civil, a forma mais justa e democrática de ocupar esse território.

Os Planos Diretores do Guarujá e Ilhabela são exemplos positivos no tocante a definição de algumas dessas regras urbanísticas. Uma solução alternativa, mas não tão eficaz, é a setorização do território para a utilização de certos instrumentos da política urbana, como fizeram as cidades de Peruíbe e Itanhaém. Ao não estabelecerem os principais parâmetros urbanísticos, os Planos Diretores perdem a chance de já garantirem o tipo de ocupação do solo que almejam para suas cidades dando margem para que leis complementares (muitas vezes elaboradas e aprovadas muito tempo depois e em outra gestão) inviabilizem as diretrizes do Plano Diretor.

A pesquisa também alerta para a falta de coerência dos Planos Diretores. De nada adianta estabelecer em seus capítulos iniciais ações que estimulam o cumprimento da função social da propriedade, se outras diretrizes do mesmo Plano forem de encontro a esse objetivo. O maior exemplo dessa falta de coerência está na reserva das melhores áreas da cidade, geralmente aquelas dotadas de infraestrutura e próximas à orla marítima, para uso estritamente residencial. Com exceção de Santos, São Vicente e Praia Grande, praticamente todos os outros Planos Diretores analisados estimulam a criação ou manutenção dessas áreas, os chamados "bairros de veraneio". Isso prejudica a dinâmica da região, aumenta os gastos públicos e gera sensação de insegurança. O PD de Mongaguá além de estimular a permanência e ampliação dessas áreas para veraneio ainda assinala a atividade turística como sendo a principal fonte de renda da cidade, perdendo a chance de estimular outras atividades econômicas e estimulando apenas o turismo de sol - tido como predatório.

\section{Referências}


BARRIOS, Sônia. A produção do espaço. In SOUZA, Adélia de e SANTOS, Milton (Org.). A construção do espaço. São Paulo: Nobel, 1986.

CAMARGO, Luiz O. Hospitalidade. São Paulo: Aleph, 2004.

CAMARGO, Luiz O. Os domínios da hospitalidade. In: DENCKER, A.; BUENO, M. (orgs.). Hospitalidade: Cenários e Oportunidades. São Paulo: Pioneira Thompson Learning, 2003.

CRUZ, Rita de Cássia A. Política de turismo e (re)ordenamento de territórios no litoral do Nordeste do Brasil. Tese de doutorado. FFLCH-USP. São Paulo, 1999.

FERRAZ, Valéria de Souza. Hospitalidade urbana em grandes cidades. São Paulo em foco. Tese de Doutorado. FAU-USP. São Paulo, 2013.

GRINOVER. Lucio. A cidade a procura da hospitalidade. São Paulo: Aleph (edição digital), 2016.

GRINOVER, Lucio. A hospitalidade, a cidade e o turismo. São Paulo: Aleph, 2007.

GUARUJÁ. Lei Complementar no 156/2013. Institui o Plano Diretor do Município de Guarujá e dá outras providências. Guarujá. Poder Executivo, 2013.

ILHABELA. Lei $n^{\circ}$ 421/2006. Dispõe sobre a Instituição do Plano Diretor Socioambiental do Município de Ilhabela e dá outras providências. Ilhabela. Poder Executivo, 2006.

ITANHAÉM. Lei Complementar $n^{\circ}$ 168/2015. Institui o Plano Diretor de Desenvolvimento do Município de Itanhaém - PDDI. Itanhaém. Poder Executivo, 2015.

MAUSS, Marcel. Sociologia e Antropologia. Volume II. SP, 2003.

MONGAGUÁ. Lei n 217/2006. Institui o Plano Diretor do Município de Mongaguá. Mongaguá. Poder Executivo, 2006.

PAIVA, Ricardo. Turismo, produção e consumo do espaço. In VARGAS, Heliana C. \& PAIVA, Ricardo (Orgs.). Turismo, arquitetura e cidade. Barueri, SP: Manole, 2016. p. $33-53$.

PERUÍBE. Lei Complementar no 100/2007. Institui o Plano Diretor, define Princípios, Objetivos, Estratégias e Instrumentos para a realização de ações 
de Planejamento Urbano de Peruíbe e dá outras providências. Peruíbe. Poder Executivo, 2007.

PRAIA GRANDE. Lei Complementar no 727/2016. Institui o Plano Diretor da Estância Balneária de Praia Grande. Praia Grande. Poder Executivo, 2016.

SANTOS. Lei Complementar $n^{\circ}$ 1.005/2018. Institui o Plano Diretor de Desenvolvimento e Expansão Urbana do Município de Santos e dá outras providências. Santos. Poder Executivo, 2018.

SÃO VICENTE. Lei Complementar $n^{\circ}$ 917/2018. Institui Plano Diretor de Desenvolvimento e Expansão Urbana do Município de São Vicente. São Vicente. Poder Executivo, 2018.

SEVERINI, Valéria F.; PANOSSO NETTO, Alexandre. Estratégias de Planejamento Urbano dos Cinco Estados mais hospitaleiros do Brasil. Anais do XVI Seminário ANPTUR. Curitiba: 2019.

SEVERINI, Valéria F.; VARGAS, Heliana C. Rediscutindo hospitalidade urbana na Lei de Zoneamento de São Paulo de 2016. Revista Hospitalidade. Volume 14. N. 02. Ago. 2017.

SEVERINI, Valéria Ferraz. Atributos espaciais de hospitalidade urbana. In VARGAS, Heliana C. \& PAIVA, Ricardo (Orgs.). Turismo, arquitetura e cidade. Barueri, SP: Manole, 2016. p. 257-285.

SEVERINI, Valéria Ferraz. Hospitalidade urbana: ampliando o conceito. Revista Iberoamericana de Turismo - RITUR, Penedo, v. 3, n.2, p. 84-99, 2013. 